\title{
Delivery of High Solubility Polyols by Vibrating Mesh Nebulizer to Enhance Mucociliary Clearance
}

\author{
John Gar Yan Chan, BPharm (Hons), ${ }^{1, \star}$ Daniela Traini, B.Sc. (Hons), Ph.D., \\ Hak-Kim Chan, BPharm (Medal), Ph.D., D.Sc., ${ }^{1}$ Paul M. Young, B.Sc. (Hons), Ph.D., \\ and Philip Chi Lip Kwok, BPharm (Hons), Ph.D.?
}

\begin{abstract}
Background: Inhaled dry powder mannitol has established in vivo therapeutic efficacy for enhancing mucociliary function. However, a single dose necessitates multiple inhalations of a sizeable powder mass. Nebulization of mannitol by vibrating mesh devices has recently been shown in vitro to impart similar dosing in a comparable or lesser treatment time. Nevertheless, the limited solubility of mannitol restricted fluid concentrations to $150 \mathrm{mg} / \mathrm{mL}$. The present study examines the feasibility of higher solubility polyols that presumably possess similar therapeutic properties to mannitol but deliverable at higher concentrations to shorten treatment time. A secondary aim is to compare delivery by two commercially available mesh nebulizers-the Aeroneb ${ }^{\circledR}$ Go and PARI eFlow Rapid.

Methods: A series of formulations containing three polyols (mannitol, sorbitol, and xylitol) of increasing concentration in $1 \% \mathrm{w} / \mathrm{v}$ sodium chloride were nebulized. Aerosol characteristics and treatment times were determined primarily by laser diffraction.

Results: Results indicate viscosity is the primary determinant of vibrating mesh nebulizer performance. For both nebulizers, xylitol $334 \mathrm{mg} / \mathrm{mL}$ exhibits the greatest osmolar output-double that of $150 \mathrm{mg} / \mathrm{mL}$ mannitol.

Conclusions: A nebulized xylitol solution has potential clinical application for promoting rapid mucociliary clearance. Both vibrating mesh nebulizers facilitate quick treatment times. Future in vivo studies would compare the efficacy of nebulized xylitol to commercial hyperosmolar agents and establish any potential polyol-associated antibacterial activity.
\end{abstract}

Key words: mucociliary clearance, nebulizer, cystic fibrosis, inhaled therapy

\section{Introduction}

$\mathbf{M}$ UCOCILIARY CLEARANCE is impaired in respiratory disease states such as cystic fibrosis (CF), bronchiectasis, and asthma due to dehydration of the airway surface liquid (ASL). ${ }^{(1-3)}$ Subsequent mucus stasis and airway obstruction provokes and exacerbates airway inflammation and infection. ${ }^{(2)}$ Moreover, the resultant airway obstruction also restricts access of critical respiratory medications into the smaller airways. ${ }^{(4)}$

Mucoactive therapy with hyperosmolar agents such as nebulized hypertonic saline, and more recently dry powder mannitol, have proven in vivo efficacy in precluding these complications by correcting the underlying hydration de- fect. ${ }^{(5)}$ The attraction of utilizing polyols (or sugar alcohols) such as mannitol, is primarily attributed to their minimal airway transepithelial permeability, which theoretically permits a longer duration of therapeutic action and their pleasant taste encouraging patient adherence. . $^{(3,6-8)}$

However, dry powder mannitol is currently administered as 40-mg capsules, with a recommended total dose of $400 \mathrm{mg}$, twice a day. ${ }^{(1,9)}$ Further, efficacious delivery is dependent on the patient's ability to inhale at a satisfactorily high flow rate, ${ }^{(7)}$ which is not always achievable by the target patients. This is understandably tedious and time-consuming, requiring multiple actuations, capsule loadings, and associated inspiratory maneuvres. The authors previously examined the feasibility of delivering mannitol as a

\footnotetext{
${ }^{1}$ Faculty of Pharmacy, The University of Sydney, Sydney, NSW, Australia.

${ }^{2}$ Department of Pharmacology \& Pharmacy, The University of Hong Kong, Hong Kong SAR, People's Republic of China.

${ }^{*}$ Corresponding author.
} 
nebulized mucoactive agent using vibrating mesh nebulizers as an alternative. ${ }^{(10)}$ These modern devices deliver therapeutic agents much quicker and more efficiently than traditional jet nebulizers. ${ }^{(11-13)}$ As CF patients generally require nebulization for delivery of various medications, it would further allow consolidation of therapy via a single mesh nebulizer device as opposed to a separate dry powder inhaler.

In this previous study ${ }^{(10)}$ it was found that a similar dose of mannitol could be delivered by nebulization, in a comparable or shorter time than required for delivery of the equivalent dry powder form. The provision being that coformulation with an electrolyte such as sodium chloride was necessary to achieve practical treatment times and realistic respirable aerosol fraction (defined as the percentage of aerosol $<5 \mu \mathrm{m})$. Mannitol alone in aqueous solution suffered from frequent intermittent nebulization and large median droplet size. Increasing sodium chloride concentrations shortened treatment times and supplemented the overall osmotic effect. Nonetheless, as mannitol is the primary osmotic agent, it was suggested sodium chloride concentration be limited to $1 \% \mathrm{w} / \mathrm{v}$ for future formulations to optimally balance treatment time with taste tolerability. However, the key issue remained that mannitol had relatively low aqueous solubility, restricting fluid concentrations in that study to $150 \mathrm{mg} / \mathrm{mL}$.

The implementation of higher solubility polyols, such as sorbitol and xylitol, as hyperosmolar agents is proposed to overcome this solubility limitation and shorten treatment time. Solubilized polyols are expected to work in a similar manner to nebulized hypertonic saline. Compared to dry powder mannitol, a nebulized mannitol formulation may increase the volume of the ASL. However, the significance of this effect would need to be determined in vivo. The proposed polyols presumably have a similar therapeutic action to mannitol, but their higher solubility would allow for delivery of a similar osmotic effect in a substantially reduced drug fluid volume. Sorbitol, as a diastereomer of mannitol, shares the same molecular weight and is expected to generate similar aerosol characteristics and effect on airway function, but able to achieve greater formulation concentrations.

Xylitol has a slightly higher osmotic value than mannitol or sorbitol and retains the low transepithelial permeability important for prolonged therapeutic effect. ${ }^{(7,8,14)}$ By way of lowering the salt concentration of the ASL, xylitol in vitro has demonstrated the potential to augment endogenous antimicrobial factors present in airway mucus. ${ }^{\left({ }^{2}\right)}$ Sajjan et al. $(2004)^{(15)}$ went further to suggest this effect may be a direct result of increased mucociliary clearance. The safety and tolerability of jet-nebulized iso-osmotic $(50 \mathrm{mg} / \mathrm{mL})$ and hypertonic (100 and $150 \mathrm{mg} / \mathrm{mL}$ ) xylitol for CF patients has been established. ${ }^{(16,17)}$ However, it is noted that jet-nebulization was lengthy, with delivery of just $1 \mathrm{~mL}$ of iso-tonic xylitol requiring $4.2 \mathrm{~min} .{ }^{(18)}$ An ongoing clinical trial compares the efficacy of hypertonic xylitol ( $5 \mathrm{~mL}$ of $15 \% \mathrm{w} / \mathrm{v}$, twice daily) to hypertonic saline ( $5 \mathrm{~mL}$ of $7 \% \mathrm{w} / \mathrm{v}$, twice daily), with the primary goal of determining the safety of xylitol and any significant decrease in airway bacterial colonization in $\mathrm{CF}$ subjects. ${ }^{(17)}$ The effect on colonization is proposed to be a result of the aforementioned decrease in ASL ionic strength. However, hypertonic xylitol for the sole purpose of enhancing mucociliary clearance has not been studied, nor has the coupling with vibrating mesh technology to substantially enhance aerosol delivery.

The current study examines the applicability of these high solubility polyols coformulated with $1 \% \mathrm{w} / \mathrm{v}$ sodium chloride as mesh nebulized mucoactive hyperosmolar agents, with a view to deliver a therapeutic dose at significantly reduced treatment time compared to dry powder mannitol, mesh nebulized mannitol, and nebulized hypertonic saline. The aerosolization characteristics of these novel polyol formulations were compared using two commercially available vibrating mesh nebulizers.

\section{Materials and Methods}

\section{Nebulizer}

Two commercially available vibrating mesh nebulizersan Aeroneb $^{\circledR}$ Go kindly provided by Aerogen (Lot 9136100319; Aerogen, Dangan, Galway, Ireland) and a PARI eFlow Rapid (Serial Number 9V11E08456; PARI GmbH, Starberg, Germany)-were used for nebulization. The nebulizers were thoroughly cleaned between nebulizations, with consideration of the manufacturers' instructions. This involved rinsing with cold tap water, followed by soaking in hot tap water for $10 \mathrm{~min}$, then rinsing with deionized water. No detergent was used to minimize potential foreign substance deposition on nebulizer components (e.g., fragrance). The nebulizers were dried using compressed air then equilibrated to ambient temperature by a deionizing fan (Serial 25724; Ion Systems, Berkeley, CA, USA) before use. Deionizing fan would mitigate any electrostatic charge on the plastic surfaces of the nebulizer that may affect aerosol performance. For the eFlow Rapid, the mesh was additionally reverse-nebulized using the provided Easycare cleaning aid (PARI GmbH, Starberg, Germany) every six nebulizations to prevent mesh clogging.

The relatively small number of nebulizations performed combined with adequate cleaning meant mesh clogging was not expected to severely affect performance of the nebulizers. Both nebulizers were retested following completion of the main experiment to ensure consistency of results that indicated minimal mesh clogging.

\section{Nebulizer fluids}

Fresh deionized water (MilliQ, Molsheim, France), sodium chloride (Batch 232931, LabServ ${ }^{\mathrm{TM}}$, Clayton, Victoria, Australia), mannitol (Batch E236A, Roquette Frères, Lestrem, France), sorbitol (Batch 603650; Unilab, Ajax Chemicals, Auburn, Australia), and xylitol (Batch 744229, Roquette Frères, Lestrem, France) were used as supplied, to prepare the following fluids (in 1\% w/v saline) for nebulization: (1) Mannitol (75 and $150 \mathrm{mg} / \mathrm{mL}$ ), for comparison with the previous study by Chan et al. $(2011){ }^{10}$ (2) Sorbitol $(75,150$, 300 , and $400 \mathrm{mg} / \mathrm{mL}$ ); (3) Xylitol at osmotic concentrations equivalent to those for sorbitol $(63,125,251$, and $334 \mathrm{mg} / \mathrm{mL}$, respectively). The chemical information and osmotic equivalence among the three polyols is presented in Tables 1 and $2,{ }^{(19-21)}$ respectively. Based on data from a previous publication, ${ }^{(10)} 1 \%$ saline was chosen as the vehicle for the polyol formulations. This concentration was proposed to impart an appropriate electrolyte concentration for realizing a practical treatment time without compromizing taste tolerability. All 
Table 1. Chemical Information for Mannitol, SORBITOL, AND XYLITOL

\begin{tabular}{llll}
\hline & D-Mannitol & D-Sorbitol & Xylitol \\
\hline CAS number & $69-65-8$ & $50-70-4$ & $87-99-0$ \\
Molecular formula & $\mathrm{C}_{6} \mathrm{H}_{14} \mathrm{O}_{6}$ & $\mathrm{C}_{6} \mathrm{H}_{14} \mathrm{O}_{6}$ & $\mathrm{C}_{5} \mathrm{H}_{12} \mathrm{O}_{5}$ \\
Molecular weight & 182.2 & 182.2 & 152.2 \\
$\begin{array}{c}\text { Water solubtiliy } \\
\left(20^{\circ} \mathrm{C}\right)(\mathrm{g} / 100 \mathrm{~mL})\end{array}$ & 18 & 220 & 160 \\
$\begin{array}{c}\text { Octanol-water partition } \\
\quad \text { coefficient }(\log P)\end{array}$ & -3.1 & -5.0 & -5.2 \\
\hline
\end{tabular}

solutions were stored at room temperature $\left(20 \pm 1^{\circ} \mathrm{C}\right)$ and used within $48 \mathrm{~h}$ of manufacture.

\section{Particle characterization and instrument selection}

Laser diffraction is a quick and well-substantiated method for size characterization of aqueous aerosols. ${ }^{(22-27)}$ Its utility as a sizing option has further been confirmed for vibrating mesh-nebulized aerosols. ${ }^{(24,28)}$ The geometric and aerodynamic diameter obtained from laser diffraction and cascade impaction (corrected for evaporation), respectively, exhibit a high level of correlation. ${ }^{(24,27)}$

Laser diffractometry with the Spraytec (Malvern, Worcestershire, UK) was used to determine aerosol distribution and total nebulization time. Air extraction through a SureGard ${ }^{\circledR} 1420$ nebulizer filter (Lot L69470; BIRD Healthcare Pty Ltd, Melbourne, Australia) was implemented to maintain laser obscuration at $20 \pm 2 \%$ and to prevent aerosol reentry into the measurement zone. A new respiratory filter was used for each nebulization. A $10-\mathrm{mm}$ gap was maintained between nebulizer mouthpiece and measurement zone in accordance with standards for particle sizing with laser diffractometry set by the European Committee for Standardization. ${ }^{(29)}$

Multiple scatter and beam steering were accounted for as follows: detectors 1-6 were excluded from data analysis to account for beam steering; an algorithm to correct for multiple scatter embedded in the Malvern software was activated, although no significant multiple scattering was expected as light transmission remained above $70 \%$ for all measurements. ${ }^{(30,31)}$ No significant vignetting was observed.

All experiments were conducted within a climate controlled room with temperature maintained at $20 \pm 1^{\circ} \mathrm{C}$ and relative humidity at $30 \pm 1 \%$. The reservoir of the Aeroneb ${ }^{\circledR}$ Go was filled with $2.5 \mathrm{~mL}$ and the eFlow Rapid with $3.5 \mathrm{~mL}$ of the respective nebulizer fluid prior to nebulization-the higher volume in the eFlow to compensate for an approxi-

Table 2. Osmole Equivalents for the Various Concentrations of Polyol Fluids

\begin{tabular}{lccc}
\hline \multirow{2}{*}{$\begin{array}{l}\text { Osmoles }\left(\times 10^{-3}\right) \\
\text { per 2.5 } \mathrm{mL}\end{array}$} & \multicolumn{3}{c}{ Polyol fluid concentration $(\mathrm{mg} / \mathrm{mL})$} \\
\cline { 2 - 4 } 1.03 & Mannitol & Sorbitol & Xylitol \\
\hline 2.06 & 75 & 75 & 63 \\
4.12 & 150 & 150 & 125 \\
5.49 & - & 300 & 251 \\
& - & 400 & 334 \\
\hline
\end{tabular}

mate $1-\mathrm{mL}$ residual volume incorporated in its medication reservoir design. The filled nebulizer was weighed, then again postnebulization, to determine gravimetric output and residual volume. Particle measurement and extraction was initiated $5 \mathrm{sec}$ prior to nebulization and ceased $10 \mathrm{sec}$ after no aerosol was detectable (detection limit at 10\% obscuration) and reservoir confirmed to be empty (Aeroneb ${ }^{\circledR} \mathrm{Go}$ ) or the polyol fluid fell below the level of the vibrating mesh plate (eFlow Rapid). Treatment time for the nebulizers was defined as the first to the last instance of detectable aerosol on the Spraytec. All data points excluding the initial and last $5 \mathrm{sec}$ of nebulization were then averaged for each measurement. The prepared nebulizer fluids (except $400 \mathrm{mg} / \mathrm{mL}$ sorbitol) were each analyzed in triplicate.

\section{Aerosol performance assessment by cascade impaction}

A series of nebulizations of two promising formulation candidates $(300 \mathrm{mg} / \mathrm{mL}$ sorbitol and $334 \mathrm{mg} / \mathrm{mL}$ xylitol, in $1 \% \mathrm{w} / \mathrm{v}$ saline) was performed on the Next Generation Impactor (NGI) using the Aeroneb ${ }^{\circledR}$ Go to assess droplet content uniformity and reconfirm the correlation with laser diffractometry. The experiments were performed in triplicate for each formulation.

To limit the evaporation of nebulized aerosol, the nebulizer and NGI were housed in a polycarbonate box with a controlled temperature $\left(20 \pm 1^{\circ} \mathrm{C}\right)$ and relative humidity ( $>95 \%$ ) to minimize aerosol evaporation. The aerosol impactions were performed at a sampling flow rate of $15 \mathrm{~L}$ $\mathrm{min}^{-1}$ to mimic the midpoint of adult tidal breathing used with nebulizers. The airflow was activated for $1 \mathrm{~min}$ prior to attachment of the nebulizer to allow for environmental equilibration between the NGI and experimental housing. A rubber adaptor completed a sealed attachment of the nebulizer to the USP throat of the NGI. Impactor plates were not coated as it is not required for collection of aqueous aerosol and a hydrophobic layer may cause unintended postdeposition movement of the aqueous drug. ${ }^{(32,33)}$

\section{Mass assay}

Following aerosol deposition, the nebulizer and NGI plates were oven dried at $70^{\circ} \mathrm{C}$ to evaporate any aqueous phase. The solid deposition was then allowed to cool to ambient temperature. The nebulizer, adaptor, USP (United States Pharmacopeia) throat and impactor plates were then separately rinsed with $20,5,5$, and $10 \mathrm{~mL}$ of mobile phase (50 mg/L calcium disodium EDTA (Sigma-Aldrich Chemie B.V., Zwijndrecht, The Netherlands) in deionized water), respectively. The various rinsing volumes reflect the expected solute mass for the sample and an appropriate dilution for chemical analysis detection. Mass assay of these samples was performed using high performance liquid chromatography (HPLC).

Methodology for chromatographic separation of sodium chloride and mannitol was adapted from Chan et al. (2011). ${ }^{10}$ The Shimadzu HPLC system was comprised of a CBM-20A controller, LC-20AT pump, SPD-20A RID-10A refractive index detector, SIL-20A HT Autosampler and column oven with LCSolution software (all Shimadzu Corporation, Kyoto, Japan). It was coupled with a dual column configuration, consisting of a Sugar-Pak ${ }^{\circledR} 300 \times 6.5 \mathrm{~mm}$ (i.d.) column 


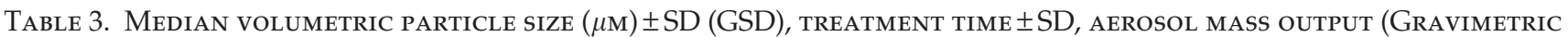
Difference Between Nebulizer Pre- and Postnebulization Weight) \pm SD and Respirable Fraction \pm SD For the Aernoeb ${ }^{\circledR}$ Go Assuming the Initial 2.5-mL Fluid Charge Was Completely Nebulized

\begin{tabular}{lcccc}
\hline Polyol fluid & Median particle size $(\mu \mathrm{m})$ & Treatment time $(\mathrm{sec})$ & Mass output $(g)$ & Respirable fraction $(\%)$ \\
\hline Mannitol $75 \mathrm{mg} / \mathrm{mL}$ & $6.0 \pm 0.04(1.9)$ & $225 \pm 1$ & $1.6 \pm 0.01$ & $41 \pm 1.1$ \\
Mannitol $150 \mathrm{mg} / \mathrm{mL}$ & $5.8 \pm 0.01(1.9)$ & $245 \pm 1$ & $1.7 \pm 0.01$ & $42 \pm 0.3$ \\
Sorbitol $75 \mathrm{mg} / \mathrm{mL}$ & $5.9 \pm 0.05(1.9)$ & $220 \pm 1$ & $1.5 \pm 0.02$ & $41 \pm 0.4$ \\
Sorbitol $150 \mathrm{mg} / \mathrm{mL}$ & $5.8 \pm 0.00(1.9)$ & $230 \pm 1$ & $1.6 \pm 0.01$ & $43 \pm 0.6$ \\
Sorbitol $300 \mathrm{mg} / \mathrm{mL}$ & $5.7 \pm 0.01(1.8)$ & $310 \pm 3$ & $1.8 \pm 0.01$ & $43 \pm 0.1$ \\
Sorbitol $400 \mathrm{mg} / \mathrm{mL}$ & $6.0(1.8)$ & 780 & $1.5 \pm 0.03$ & 40 \\
Xylitol $62.6 \mathrm{mg} / \mathrm{mL}$ & $5.9 \pm 0.03(1.9)$ & $215 \pm 3$ & $1.6 \pm 0.01$ & $41 \pm 0.2$ \\
Xylitol $125.3 \mathrm{mg} / \mathrm{mL}$ & $5.7 \pm 0.03(1.9))$ & $230 \pm 3$ & $1.7 \pm 0.01$ & $43 \pm 0.3$ \\
Xylitol $250.6 \mathrm{mg} / \mathrm{mL}$ & $5.7 \pm 0.02(1.9)$ & $320 \pm 1$ & $1.8 \pm 0.01$ & $43 \pm 0.2$ \\
Xylitol $334.1 \mathrm{mg} / \mathrm{mL}$ & $5.9 \pm 0.02(1.9)$ & & $42 \pm 0.2$ \\
\hline
\end{tabular}

$\mathrm{SD}$, standard deviation.

maintained at $77 \pm 1^{\circ} \mathrm{C}$ by a column heater, joined to a Resolve ${ }^{\circledR}$ C-18 column $150 \times 3.9 \mathrm{~mm}$ (all Waters, Milford, MA, USA). A mobile phase consisting of $50 \mathrm{mg} / \mathrm{mL}$ calcium disodium EDTA in deionized water was pumped through the system at a flow rate of $0.5 \mathrm{~mL} \cdot \mathrm{min}^{-1}$, with a sample injection volume of $100 \mu \mathrm{L}$.

Sodium chloride, sorbitol, or xylitol were separately dissolved in deionized water at sequential concentrations to obtain calibration curves- 0.01 to $1 \% \mathrm{w} / \mathrm{v}\left(R^{2}=1.00\right)$ for sodium chloride; 0.015 to $15 \mathrm{mg} / \mathrm{mL}\left(R^{2}=1.00\right)$ for both sorbitol and xylitol—for result analysis.

\section{Viscosity measurement}

The viscosity of the various nebulized fluids was determined using a Ubbelohde glass capillary viscometer (Size 0B; Serial 67795) (Poulten Selfe \& Lee Ltd, Essex, UK). Utilization of the viscometer involved drawing the sample fluid up the capillary of the secondary bulb on the viscometer then releasing the fluid and measuring the time taken for it to reach a fixed line. The time was then used to calculate the viscosity. Measurements were performed in triplicate at $20 \pm 1^{\circ} \mathrm{C}$ (room temperature) and in a cold room at $5 \pm 1^{\circ} \mathrm{C}$ (refrigerated temperature).

\section{Statistical analysis}

One-way analysis of variance (ANOVA) was used to identify any statistically significant differences between the various fluid formulations $(p<0.05)$. Significant differences were further analyzed with Tukey's post hoc test to identify the specific formulations involved. A $p$-value of $<0.05$ was considered statistically significant.

\section{Results}

\section{Laser diffraction}

The results from laser diffraction are presented in Table 3 (Aeroneb ${ }^{\circledR}$ Go) and Table 4 (eFlow Rapid). Sorbitol 400 mg/ $\mathrm{mL}$ in $1 \% \mathrm{w} / \mathrm{v}$ saline was assessed once only for both nebulizers as the rate of aerosolization dropped far too significantly (no detection at all was observed for the eFlow Rapid) to be considered as a potential candidate for future study.

For the Aeroneb ${ }^{\circledR}$ Go, median particle size $(5.7-6.9 \mu \mathrm{m})$ mainly decreases with polyol concentration but increases again at high concentrations $(>300 \mathrm{mg} / \mathrm{mL}$ for sorbitol and $>251 \mathrm{mg} / \mathrm{mL}$ for xylitol). The respirable fraction $(40-43 \%)$ is directly related to particle size. However, although these characteristics were statistically significant $(p$-value $<0.05)$, they are clinically negligible. In contrast, nebulizations on the

Table 4. Median Volumetric Particle Size $(\mu \mathrm{M}) \pm S D(G S D)$, Treatment Time $\pm S D$, Aerosol Mass Output (Gravimetric Difference Between Nebulizer Pre- and Postnebulization Weight) \pm SD and Respirable Fraction \pm SD for the eFlow Rapid Assuming the Initial 3.5 mL Fluid Charge ( -1 mL Residual Volume) Was Completely Nebulized

\begin{tabular}{lcccc}
\hline Polyol fluid & Median particle size $(\mu \mathrm{m})$ & Treatment time $(\mathrm{s})$ & Mass output $(\mathrm{g})$ & Respirable fraction $(\%)$ \\
\hline Mannitol $75 \mathrm{mg} / \mathrm{mL}$ & $4.6 \pm 0.05(1.6)$ & $104 \pm 1$ & $2.4 \pm 0.03$ & $56 \pm 0.3$ \\
Mannitol $150 \mathrm{mg} / \mathrm{mL}$ & $4.1 \pm 0.09(1.9)$ & $130 \pm 1$ & $2.5 \pm 0.03$ & $64 \pm 1.9$ \\
Sorbitol $75 \mathrm{mg} / \mathrm{mL}$ & $4.5 \pm 0.03(1.6)$ & $160 \pm 1$ & $2.4 \pm 0.03$ & $58 \pm 1.2$ \\
Sorbitol $150 \mathrm{mg} / \mathrm{mL}$ & $4.1 \pm 0.09(1.6)$ & $150 \pm 1$ & $2.5 \pm 0.06$ & $65 \pm 1.6$ \\
Sorbitol $300 \mathrm{mg} / \mathrm{mL}$ & $3.6 \pm 0.09(1.4)$ & $230 \pm 3$ & $2.5 \pm 0.05$ & $77 \pm 2.4$ \\
Sorbitol $400 \mathrm{mg} / \mathrm{mL}$ & - & $155 \pm 3$ & $2.4 \pm 0.03$ & $53 \pm 2.1$ \\
Xylitol $62.6 \mathrm{mg} / \mathrm{mL}$ & $4.7 \pm 0.02(1.7)$ & $180 \pm 3$ & $2.4 \pm 0.04$ & $63 \pm 1.6$ \\
Xylitol $125.3 \mathrm{mg} / \mathrm{mL}$ & $4.2 \pm 0.07(1.6)$ & $230 \pm 2$ & $2.5 \pm 0.07$ & $70 \pm 1.1$ \\
Xylitol $250.6 \mathrm{mg} / \mathrm{mL}$ & $3.9 \pm 0.06(1.5)$ & $280 \pm 1$ & $2.5 \pm 0.05$ & $80 \pm 1.2$ \\
Xylitol $334.1 \mathrm{mg} / \mathrm{mL}$ & $3.6 \pm 0.08(1.4)$ & & & \\
\hline
\end{tabular}

${ }^{\mathrm{a}}$ No aerosol detected for Sorbitol $400 \mathrm{mg} / \mathrm{mL}$.

$\mathrm{SD}=$ standard deviation. 


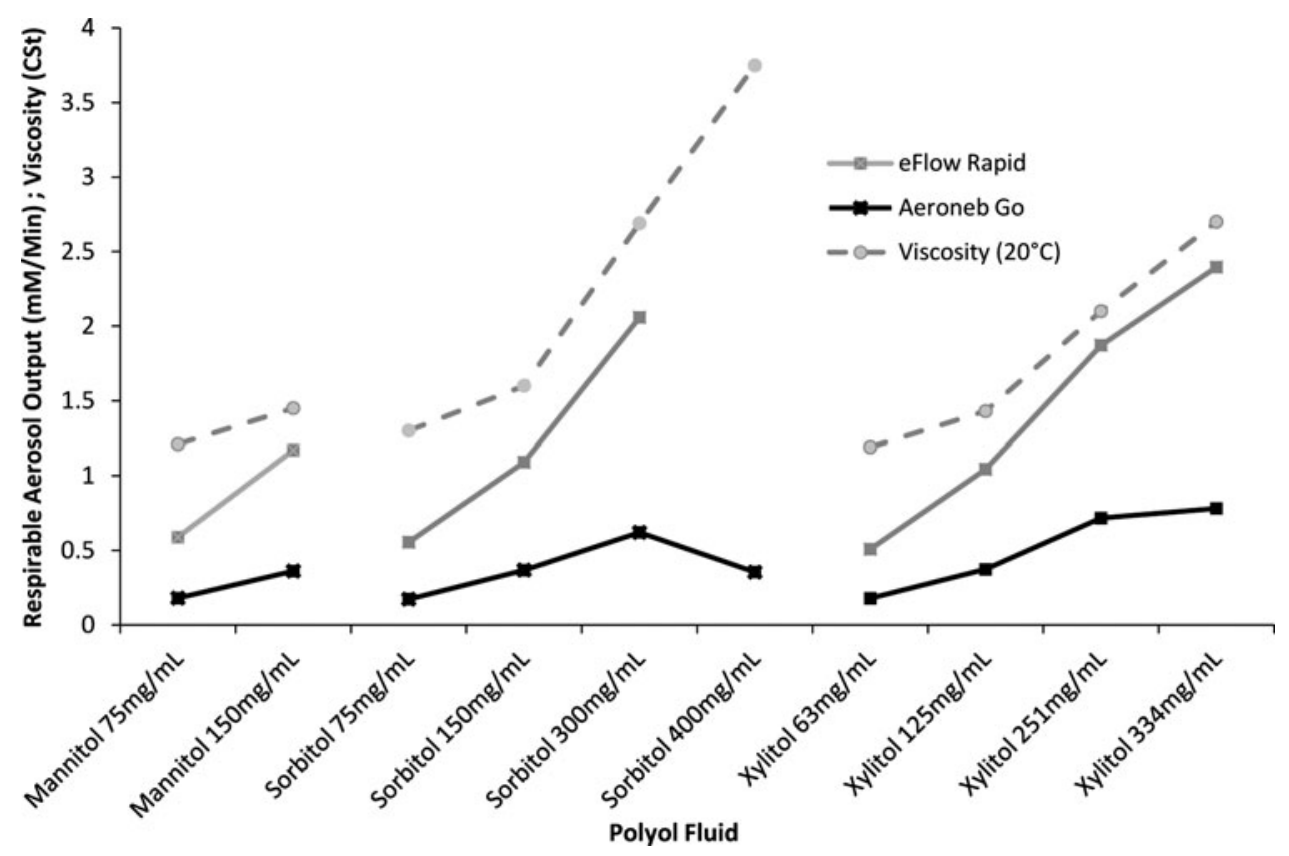

FIG. 1. Respirable aerosol output and viscosity (at $20^{\circ} \mathrm{C}$ ) for nebulized polyol fluids (error is not charted as error bars are too small to be visible).

eFlow Rapid imparted considerable changes in particle size $(3.6-4.7 \mu \mathrm{m})$ and respirable fraction $(53-80 \%)$ related to polyol concentrations. For both nebulizers, treatment times were directly correlated to polyol concentration. Sorbitol at $400 \mathrm{mg} / \mathrm{mL}$ exhibited a disproportionately high treatment time compared to concentrations at $\leq 300 \mathrm{mg} / \mathrm{mL}$.

There was also a slight increase in mass output with polyol concentration for the Aeroneb ${ }^{\circledR}$ Go. For this nebulizer, it is important to note that all charged fluid $(2.5 \mathrm{~mL}$, weighing approximately $2.5 \mathrm{~g}$ ) is nebulized. Loss of mass measured postaerosolization, represents significant droplet impaction and deposition at the base of the nebulizer chamber. Conversely, the eFlow Rapid nebulizes until reaching an in-built residual volume of approximately $1 \mathrm{~mL}$, and there is minimal loss by deposition within the device.

Figure 1 shows the osmolar output rate of respirable sized aerosol for various polyol formulations. Comparable output between polyol formulations at the lower two concentrations $(75 \mathrm{mg}$ and $150 \mathrm{mg} / \mathrm{mL}$ mannitol and sorbitol; 63 and $125 \mathrm{mg} / \mathrm{mL}$ xylitol) was observed. For both nebulizers, maximum output rate was achieved at a concentration of $300 \mathrm{mg} / \mathrm{mL}$ for sorbitol and $334 \mathrm{mg} / \mathrm{mL}$ for xylitol, the latter formulation approximately doubling the output relative to $150 \mathrm{mg} / \mathrm{mL}$ mannitol.

\section{Cascade impaction}

Comparison of important values between cascade impaction and laser diffraction for $300 \mathrm{mg} / \mathrm{mL}$ sorbitol and $334 \mathrm{mg} / \mathrm{mL}$ xylitol, in $1 \% \mathrm{w} / \mathrm{v}$ saline is illustrated in Table 5. The median particle size for the xylitol formulation showed a clear correlation between the two sizing methods. There was a statistically significant difference $(p$-value $<0.05)$ between the methods for the sorbitol fluid but is not considered clinically significant. The geometric standard deviation and aerosolized mass also demonstrated slight differences.

Figures 2 and 3 depict the mean aerosol mass distribution for the two aforementioned formulations recovered by mass assay. In both cases, no sizeable differences were observed between the respective proportions of polyol and sodium chloride.

\section{Fluid viscosity}

The viscosity of the various polyol fluids is presented in Table 6. Viscosity increases with polyol concentration for all fluids and is inversely related to temperature. At both room and refrigerated temperatures, sorbitol solutions shares similar viscosity values with the mannitol formulations. Both these polyols exhibit slightly higher viscosity at all equivalent osmolar concentrations relative to the xylitol solutions.

\section{Discussion}

The physicochemical properties of fluids for nebulization affect aerosol generation, particularly for vibrating mesh type nebulizers. ${ }^{(34)}$ Of primary importance is the high electrostatic charge present in aqueous solutions that work to inhibit the flow and detachment of fluid through the mesh. ${ }^{(35-37)}$ Introduction of an electrolyte suppresses this

Table 5. Comparison of Median Particle Size, Geometric Standard Deviation, and Aerosol Mass BetweEn CASCAde IMPACTION AND LASER DiFFRACTION FOR 300 MG/ML SORBITOL, AND 334 Mg/ML XYlitol, IN 1\% SAline

\begin{tabular}{lccr}
\hline & $\begin{array}{c}\text { Median } \\
\text { particle } \\
\text { size }(\mu \mathrm{m})\end{array}$ & $\begin{array}{c}\text { Geometric } \\
\text { standard } \\
\text { deviation }\end{array}$ & $\begin{array}{c}\text { Aerosol } \\
\text { mass } \\
\text { output }(g)\end{array}$ \\
\hline $\begin{array}{l}\text { Sorbitol } 300 \mathrm{mg} / \mathrm{mL} \\
\text { Laser diffraction }\end{array}$ & $5.7 \pm 0.01$ & $1.8 \pm 0.00$ & $1.8 \pm 0.01$ \\
Cascade impaction & $5.9 \pm 0.08$ & $2.1 \pm 0.10$ & $1.75 \pm 0.00$ \\
$\begin{array}{l}\text { Xylitol 334.1 mg/mL } \\
\text { Laser diffraction }\end{array}$ & $5.9 \pm 0.02$ & $1.9 \pm 0.01$ & $1.8 \pm 0.01$ \\
Cascade impaction & $5.9 \pm 0.05$ & $2.2 \pm 0.01$ & $1.76 \pm 0.00$ \\
\hline
\end{tabular}


FIG. 2. Mass distribution for sorbitol $300 \mathrm{mg} / \mathrm{mL}$ in $1 \%$ saline (error bars not shown as negligible).

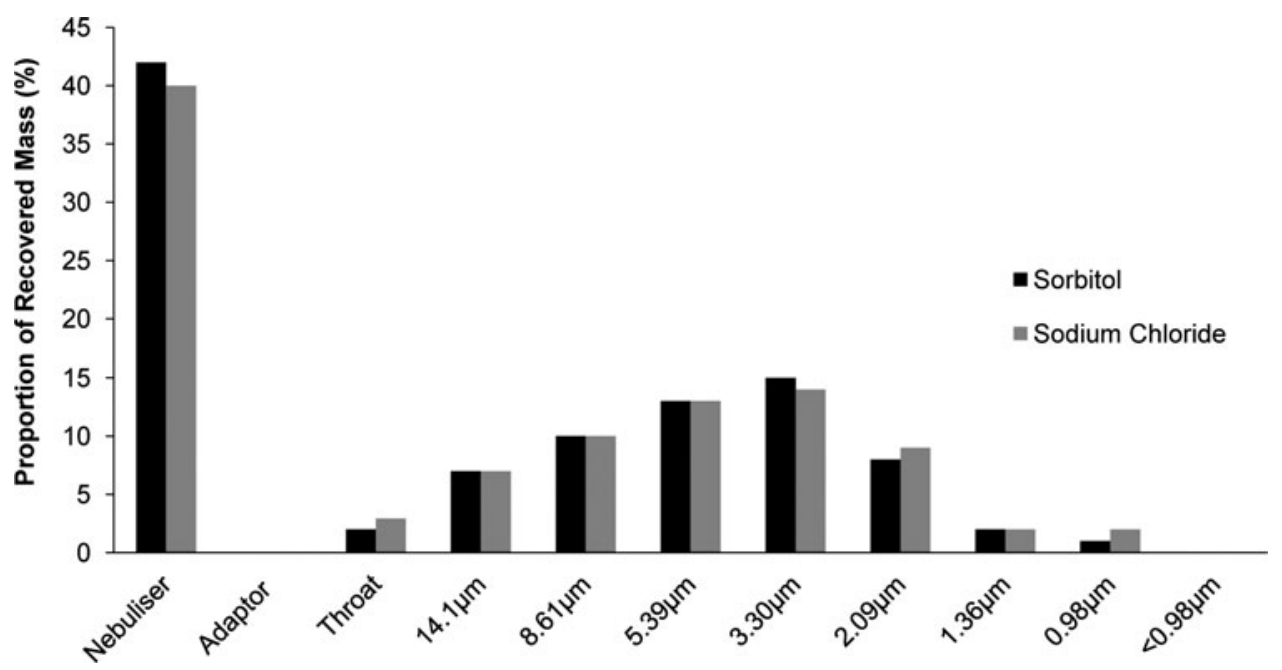

charge, considerably improving particle size and treatment times. ${ }^{(10,37,38)}$ In the current study, this was accounted for by the obligatory $1 \% \mathrm{w} / \mathrm{v}$ saline component in the various polyol formulations.

The key fluid property determining nebulizer performance in the current study is thus proposed to be viscosity, which increases with increasing polyol concentration in aqueous solutions. ${ }^{(39)}$ Increasing viscosity decreases droplet size, but is countered by prolonged treatment time as seen for both nebulizers in Tables 3 and 4. Further, nebulization slows down or completely halts at a viscosity value dependent on the mesh nebulizer. ${ }^{(38)}$ Indeed, this relationship was observed for the highest sorbitol concentration. A marked drop in output (Aeroneb ${ }^{\circledR}$ Go) or a nondetectable level of aersolization (eFlow Rapid) is eventually observed at $400 \mathrm{mg} / \mathrm{mL}$ (Fig. 1), the fluid viscosity (3.8 $\pm 0.01 \mathrm{cSt}$ ) presumably having exceeded the aforementioned critical value. For both nebulizers, xylitol output plateaus at the equivalent of $400 \mathrm{mg} / \mathrm{mL}$ sorbitol ( $334 \mathrm{mg} / \mathrm{mL}$ xylitol) without reaching the same precipitous decline in output seen for sorbitol. This similarity in output may be attributed to its lower relative molecular mass permitting greater osmolar equivalence with a lower solute mass, and hence, lesser contribution to viscosity $(2.7 \pm 0.01 \mathrm{cSt}$ for $334 \mathrm{mg} / \mathrm{mL}$ xylitol). Furthermore, the rate of viscosity increase is slower for the equivalent xylitol concentrations (Fig. 1). The critical viscosity for the Aeroneb ${ }^{\circledR}$ Go and eFlow Rapid is thus inferred to be at a point between 2.7 and $3.8 \mathrm{cSt}$. It is further noted that the solute concentrations of the sorbitol and xylitol sample fluids were considerably below their saturation points. Thus, whereas for mannitol the limiting aspect was aqueous solubility, viscosity is the ultimate factor determining maximal feasible fluid concentration for sorbitol and xylitol.

Both xylitol and sorbitol achieved superior osmolar output compared to solubilized mannitol. These higher outputs were observed at concentrations beyond the osmolar equivalent of $150 \mathrm{mg} / \mathrm{mL}$ mannitol, confirming the importance of high polyol solubility for realizing enhanced dosing capabilities. At $334 \mathrm{mg} / \mathrm{mL}$ xylitol the osmolar output is double of that achieved with $150 \mathrm{mg} / \mathrm{mL}$ mannitol (Fig. 1). However, both the nebulizers have clear differences in performance. The shorter treatment time of the eFlow Rapid may be explained by its significantly greater number of mesh holes (four times that of the Aeroneb ${ }^{\circledR}$ Go), which directly
FIG. 3. Mass distribution for xylitol $334 \mathrm{mg} / \mathrm{mL}$ in $1 \%$ saline (error not shown as negligible).

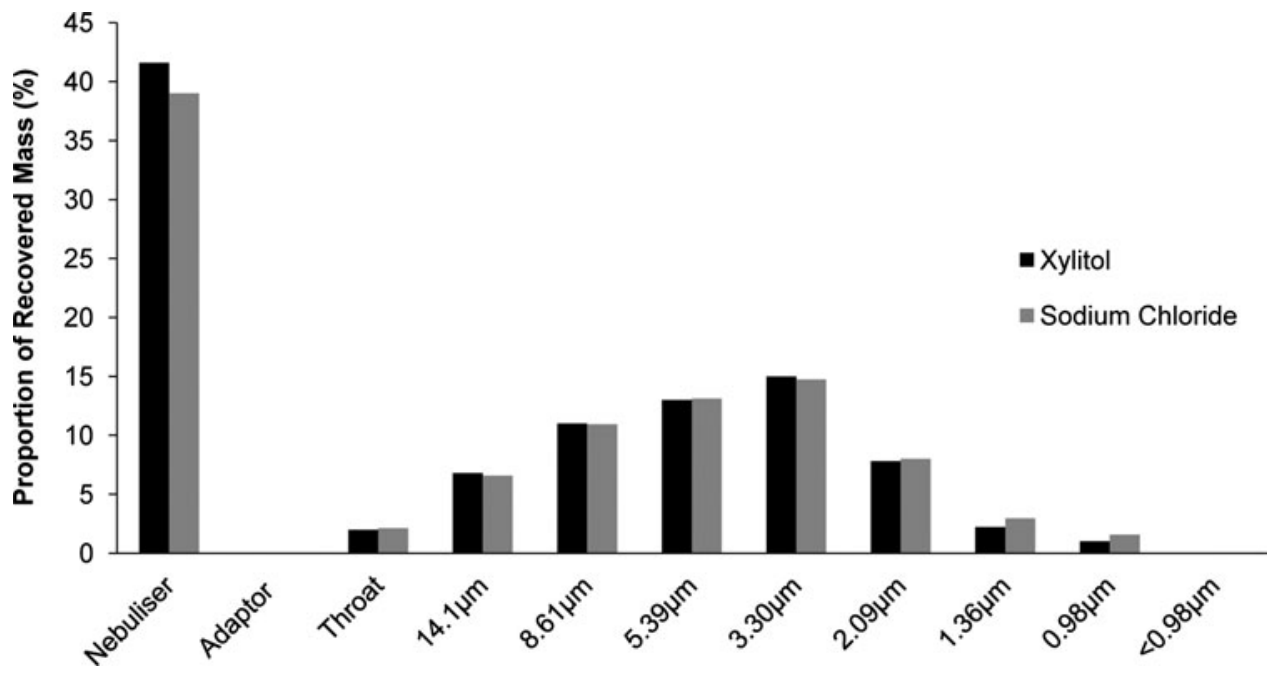




\section{Table 6. Viscosity of Polyols of Various CONCENTRATIONS AT ROOM AND REFRIGERATED TEMPERATURES}

\begin{tabular}{lcc}
\hline Polyol fluid & $\begin{array}{c}\text { Viscosity at } \\
20^{\circ} \mathrm{C} \text { (CSt) }\end{array}$ & $\begin{array}{c}\text { Viscosity at } \\
5^{\circ} \mathrm{C} \text { (CSt) }\end{array}$ \\
\hline Mannitol $75 \mathrm{mg} / \mathrm{mL}$ & $1.2 \pm 0.01$ & $1.9 \pm 0.01$ \\
Mannitol $150 \mathrm{mg} / \mathrm{mL}$ & $1.5 \pm 0.01$ & $2.5 \pm 0.01$ \\
Sorbitol $75 \mathrm{mg} / \mathrm{mL}$ & $1.3 \pm 0.01$ & $1.8 \pm 0.01$ \\
Sorbitol $150 \mathrm{mg} / \mathrm{mL}$ & $1.6 \pm 0.01$ & $2.4 \pm 0.01$ \\
Sorbitol $300 \mathrm{mg} / \mathrm{mL}$ & $2.7 \pm 0.01$ & $3.9 \pm 0.01$ \\
Sorbitol $400 \mathrm{mg} / \mathrm{mL}$ & $3.8 \pm 0.01$ & $6.4 \pm 0.01$ \\
Xylitol $62.6 \mathrm{mg} / \mathrm{mL}$ & $1.2 \pm 0.01$ & $1.7 \pm 0.01$ \\
Xylitol $125.3 \mathrm{mg} / \mathrm{mL}$ & $1.4 \pm 0.01$ & $2.1 \pm 0.01$ \\
Xylitol $250.6 \mathrm{mg} / \mathrm{mL}$ & $2.1 \pm 0.01$ & $3.1 \pm 0.01$ \\
Xylitol $334.1 \mathrm{mg} / \mathrm{mL}$ & $2.7 \pm 0.01$ & $4.4 \pm 0.01$ \\
\hline
\end{tabular}

relates to the number of aerosol droplets generated per time and hence output rate. ${ }^{(40)}$ Further, the smaller droplet sizes compared to the Aeroneb ${ }^{\circledR}$ Go are presumeably due to smaller mesh hole sizes that also confer significantly greater susceptibility to viscosity changes (Tables 3 and 4). These characteristics are observed in the high respirable fractions for the eFlow Rapid that ranges between 53 and 80\%. Differences in geometric standard deviation between the various formulations are minor and unlikely to be of clinical significance. Thus, xylitol may be a preferable alternative to nebulized mannitol that substantially improves the efficiency of hyperosmolar delivery without appreciably altering aerosol properties.

The results of cascade impaction for the Aeroneb ${ }^{\circledR}$ Go demonstrate good overall correlation with laser diffraction. Variation in the geometric standard deviation are expected due to detector exclusion in laser diffraction measurements to account for beam steering. ${ }^{(10)}$ More importantly, mass assay did not show any significant separation between sorbitol and sodium chloride (Fig. 2) or xylitol and sodium chloride (Fig. 3). This suggests the combination of the solutes did not adversely affect the capability to deliver a uniform dose of polyol throughout the course of nebulization.

A recurring issue is the visible deposition, and hence loss, of aerosol within the chamber of the Aeroneb ${ }^{\circledR}$ Go as a consequence of downward aerosol velocity (Table 3 ). This loss of aerosol may function analogous to the in-built 1-mL residual volume of the eFlow Rapid that functions to prevent patient overdosing by restricting total aerosol delivery amount to that of a less efficient jet nebulizer. Nonetheless, the Aeroneb ${ }^{\circledR}$ Go was employed as it demonstrates consistent performance in aerosol characteristics and output rate that are useful for in vitro reproducibility and comparisons. However, for in vivo studies, the greater aerosol delivery efficiency of the eFlow Rapid may be preferred.

The present study has established xylitol as having the greatest potential among the sampled polyols for nebulized delivery using a mesh device. Increasing electrolyte concentration would decrease treatment times while simultaneously boosting the osmotic effect of the formulation. ${ }^{(10)}$ It is noted that increasing ASL salt concentration may suppress endogenous airway immune factors. ${ }^{(8)}$ However, the effect on respiratory defence is not expected to be problematic, as safety of hypertonic saline for cystic fibrosis patients is already well established. In addition, the indication for xylitol in the current study is to enhance mucociliary clearance, which in itself is expected to enhance bacterial clearance.

In vivo studies are necessary to titrate sodium chloride concentrations according to patient taste tolerability.

In vivo studies are further required also to determine the effective dose for nebulized xylitol, support its efficacy for enhancing mucociliary clearance and compare its performance to other hyperosmolar agents. The retention time of jet-nebulized iso-osmotic xylitol in the airway of healthy human subjects is reported to be only three hours, which was significantly less than those determined from in vitro studies. ${ }^{(41)}$ Comparison to the study by the current authors, ${ }^{(10)}$ is, however, limited for reasons including a notably prolonged mean nebulization time $(48 \mathrm{~min})$, a significantly lower concentration $(10 \mathrm{~mL}, 5 \% \mathrm{w} / \mathrm{v})$ of nebulized xylitol fluid, and delivery by jet nebulization, which is expected to have inferior lung delivery compared to vibrating mesh technology. Moreover, the epithelial integrity and permeability of respiratory systems in CF patients are likely different to those of a healthy subject further affecting xylitol retention times.

Increasing viscosity of polyol aqueous solutions with polyol concentration was the ultimate limiting factor, causing an abrupt drop in nebulizer performance beyond a critical viscosity as demonstrated by sorbitol at $400 \mathrm{mg} / \mathrm{mL}$. Although the formulations are expected to be stable and unlikely to require refrigeration, colder storage conditions, if used, would increase viscosity (Table 6), which could potentially limit viability of the higher polyol concentrations. It is anticipated that the current coformulated electrolyte concentration ( $1 \%$ sodium chloride) may be increased in future studies to shorten treatment times while boosting osmotic delivery.

\section{Conclusions}

The present study clearly demonstrates that utilizing higher solubility polyols, especially xylitol, is a viable method of enhancing the rate of therapeutic osmolar delivery by mesh nebulization. Xylitol exhibited the greatest potential for clinical application, with $334 \mathrm{mg} / \mathrm{mL}$ xylitol doubling the output achieved by near-saturated mannitol solution (150 mg/mL). Administration of polyols in the current study is primarily aimed at vibrating mesh nebulizers, with both of the tested devices being able to facilitate rapid delivery times. However, the higher cost of vibrating mesh nebulizers could be prohibitive for some patients who may instead prefer jet nebulization or dry powder mannitol.

\section{Acknowledgments}

The authors thank Aerogen for generously providing the Aeroneb $^{\circledR}$ Go nebulizer used in this study.

\section{Author Disclosure Statement}

The authors declare that no conflicting financial interests exist.

\section{References}

1. Bilton D, Robinson P, Cooper P, Gallagher C, Kolbe J, and Charlton B: Phase III study of inhaled dry powder mannitol ("Bronchitol") in cystic fibrosis results from the 6 month 
open label phase. Am J Respir Crit Care Med. 2010; 181:A2338.

2. Daviskas E, Anderson SD, Eberl S, and Young IH: Beneficial effect of inhaled mannitol and cough in asthmatics with mucociliary dysfunction. Respir Med. 2010;104:1645-1653.

3. Daviskas E, Anderson SD, Jaques A, and Charlton B: Inhaled mannitol improves the hydration and surface properties of sputum in patients with cystic fibrosis. Chest. 2010;137: 861-868.

4. Heijerman H, Westerman E, Conway S, and Touw D: Inhaled medication and inhalation devices for lung disease in patients with cystic fibrosis: a European consensus. J Cystic Fibros. 2009;8:295-315

5. Thelin WR, and Boucher RC: The epithelium as a target for therapy in cystic fibrosis. Curr Opin Pharmacol. 2007;7: 290-295.

6. Minasian C, Wallis C, Metcalfe C, and Bush A: Comparison of inhaled mannitol, daily rhDNase and a combination of both in children with cystic fibrosis: a randomised trial. Thorax. 2010;65:51-56.

7. Bye PTP, and Elkins MR: Other mucoactive agents for cystic fibrosis. Paediatr Respir Rev. 2007;8:30-39.

8. Zabner J, Seiler MP, Launspach JL, Karp PH, Kearney WR, Look DC, Smith JJ, and Welsh MJ: The osmolyte xylitol reduces the salt concentration of airway surface liquid and may enhance bacterial killing. Proc Natl Acad Sci USA. 2000;97:11614-11619.

9. Goralski JL, Boucher RC, and Button B: Osmolytes and ion transport modulators: new strategies for airway surface rehydration. Curr Opin Pharmacol. 2010;10:294-299.

10. Chan JGY, Kwok PCL, Young PM, Chan H-K, and Traini D: Mannitol delivered by vibrating mesh nebulisation for enhancing mucociliary clearance. J Pharmaceut Sci. 2011;100: 2693-2702.

11. Hess DR: Aerosol delivery devices in the treatment of asthma. Respir Care. 2008;53:699-725.

12. Lass JS, Sant A, and Knoch M: New advances in aerosolised drug delivery: vibrating membrane nebuliser technology. Expert Opin Drug Deliv. 2006;3:693-702.

13. Waldrep JC, and Dhand R: Advanced nebulizer designs employing vibrating mesh/aperture plate technologies for aerosol generation. Curr Drug Deliv. 2008;5:114-119.

14. Bensouissi A, Roge B, and Mathlouthi M: Effect of conformation and water interactions of sucrose, maltitol, mannitol and xylitol on their metastable zone width and ease of nucleation. Food Chem. 2010;122:443-446.

15. Sajjan U, Moreira J, Liu M, Humar A, Chaparro C, Forstner J, and Keshavjee S: A novel model to study bacterial adherence to the transplanted airway: inhibition of Burkholderia cepacia adherence to human airway by dextran and xylitol. J Heart Lung Transplant. 2004;23:1382-1391.

16. Durairaj L, Launspach J, Watt JL, Mohamad Z, Kline J, and Zabner J: Safety assessment of inhaled xylitol in subjects with cystic fibrosis. J Cystic Fibros. 2007;6:31-34.

17. Zabner J, Durairaj L, and Launspach J: Clinical trial: aerosolized hypertonic xylitol versus hypertonic saline in cystic fibrosis (CF) subjects. Uo Iowa, trans. National Clinical Trial ID: NCT00928135, 2011.

18. Durairaj L, Launspach J, Watt JL, Businga TR, Kline JN, Thorne PS, and Zabner J: Safety assessment of inhaled xylitol in mice and healthy volunteers. Respir Res. 2004;5:13.

19. Rytting E, Lentz KA, Chen XQ, Qian F, and Vakatesh S: Aqueous and cosolvent solubility data for drug-like organic compounds. AAPS J. 2005;7:E78-E105.
20. Iborra JL, Obon JM, Manjon A, and Canovas M: Water concentration and activity effects on aminocylase in aqueous/organic one-liquid-phase systems. Biocatalyst. 1992;7:37-48.

21. Hoekman JD, and Ho RJ: Effects of localized hydrophilic mannitol and hydrophobic nelfinavir administration targeted to olfactory epithelium on brain distribution. AAPS PharmSciTech. 2011;12:534-543.

22. Clark AR: The use of laser diffraction for the evaluation of the aerosol clouds generated by medical nebulizers. Int J Pharmaceut. 1995;115:69-78.

23. de Boer AH, Gjaltema D, Hagedoorn P, and Frijlink HW: Characterization of inhalation aerosols: a critical evaluation of cascade impactor analysis and laser diffraction technique. Int J Pharmaceut. 2002;249:219-231.

24. Keller M, Tservistas M, Bucholski A, Hug M, and Knoch M: Correlation of laser diffraction and cascade impaction data for aqueous solutions aerosolized by the eFlow ${ }^{\circledR}$ electronic nebulizer (poster). In: Respiratory Drug Delivery. Vol X: Boca Raton, FL; pp. 745-748, 2006.

25. Mitchell JP, and Tservistas M: Laser diffractometry and cascade impaction for nebulizer product characterization. Pharmeur Sci Notes. 2006;2006:49-52.

26. Vecellio L, Grimbert D, Becquemin MH, Boissinot E, Le Pape A, Lemarié E, and Diot P: Validation of laser diffraction method as a substitute for cascade impaction in the european project for a nebulizer standard. J Aerosol Med. 2001; 14:107-114.

27. Ziegler J, and Wachtel H: Comparison of cascade impaction and laser diffraction for particle size distribution measurements. J Aerosol Med. 2005;18:311-324.

28. Rao N, Kadrichu N, and Ament B: Application of a droplet evaporation model to aerodynamic size measurement of drug aerosols generated by a vibrating mesh nebulizer. J Aerosol Med Pulmon Drug Deliv. 2010;23:295-302.

29. CEN-Nebulizer Standard EN 13544-1. Respiratory Therapy Equipment-Part 1: Nebulizing Systems and Their Components. Annex DD Method for Characterization of Nebulizers with Respect to Droplet Size Using Laser Diffraction; 2001.

30. Dumouchel C, Yongyingsakthavorn P, and Cousin J: Light multiple scattering correction of laser-diffraction spray dropsize distribution measurements. Int J Multiphase Flow. 2009; 35:277-287.

31. Martin AR, Gleske J, Katz IM, Hartmann M, Mullinger B, Haussermann S, Caillibotte G, and Scheuch G: Laser diffraction characterization of droplet size distributions produced by vibrating mesh nebulization in air and a helium-oxygen mixture. J Aerosol Sci. 2010;41:1159-1166.

32. Berg E, Svensson JO, and Asking L: Determination of nebulizer droplet size distribution: a method based on impactor refrigeration. J Aerosol Med. 2007;20:97-104.

33. Kwok PCL, Trietsch SJ, Kumon M, and Chan H-K: Electrostatic charge characteristics of jet nebulized aerosols. J Aerosol Med Pulmonary Drug Deliv. 2010;23:149-159.

34. Elhissi AMA, Karnam KK, Danesh-Azari MR, Gill HS, and Taylor KMG: Formulations generated from ethanol-based proliposomes for delivery via medical nebulizers. J Pharm Pharmacol. 2006;58:887-894.

35. Deshpande D, Blanchard J, Srinivasan S, Fairbanks D, Fujimoto J, Sawa T, Wiener-Kronish J, Schreier H, and Gonda I: Aerosolization of lipoplexes using AERx ${ }^{\circledR}$ pulmonary delivery system. AAPS J. 2002;4:12-21.

36. Rosell J, Schuster J, Gonda I, and Liu K: Electrostatic charge in AERX ${ }^{\mathrm{TM}}$ aerosols. J Aerosol Med. 2001;14:405. 
37. Zhang G, David A, and Wiedmann TS: Performance of the vibrating membrane aerosol generation device: Aeroneb Micropump Nebulizer. J Aerosol Med. 2007;20: 408-416.

38. Ghazanfari T, Elhissi AM, Ding Z, and Taylor KM: The influence of fluid physicochemical properties on vibratingmesh nebulization. Int J Pharm. 2007;339:103-111.

39. Zhu C, Ma Y, and Zhou C: Densities and viscosities of sugar alcohol aqueous solutions. J Chem Eng Data. 2010;55:38823885.

40. Vecellio L: The Mesh Nebuliser: a recent technical innovation for aerosol delivery. Breathe. 2006;2:253-260.

41. Durairaj L, Neelakantan S, Launspach J, Watt JL, Allaman MM, Kearney WR, Veng-Pedersen $\mathrm{P}$, and Zabner J: Bronchoscopic assessment of airway retention time of aerosolized xylitol. Respir Res. 2006;7:27.
Received on December 2, 2011

in final form, January 11, 2012

Reviewed by: James Blanchard

Peter Valberg

Address correspondence to: John Gar Yan Chan Faculty of Pharmacy

The University of Sydney

S211, Pharmacy \& Bank Building A15 Sydney, NSW 2005, Australia

E-mail: jcha5503@uni.sydney.edu.au 